\title{
A SIMULATION FRAMEWORK FOR UAV-AIDED HUMANITARIAN LOGISTICS
}

\author{
Robert van Steenbergen \\ Martijn Mes \\ Department of Industrial Engineering and Business Information Systems \\ University of Twente \\ P.O. Box 217 \\ 7500 AE Enschede, THE NETHERLANDS
}

\begin{abstract}
This paper presents a generic simulation framework for the evaluation of humanitarian logistics, which can easily be tailored to a specific disaster scenario. Within the framework, various methods can be implemented for the planning and control of vehicles in affected areas. The aim is to explore how emerging technologies, specifically Unmanned Aerial Vehicles (UAVs), can contribute to humanitarian logistics. We illustrate the application of the framework by modeling the distribution of relief goods after the earthquake on Sulawesi, Indonesia in 2018.
\end{abstract}

\section{INTRODUCTION}

Demand for efficient and effective humanitarian logistics is increasing due to three reasons. First, there are more frequent and worse disasters leading to more people in need of humanitarian assistance (OCHA 2019). Second, the amount of people living in disaster-prone areas in developing countries is increasing due to urbanization, population growth and land shortage, leading to higher numbers of victims when disasters strike (Dilley et al. 2005). Third, logistics efforts account for $60 \%-80 \%$ of disaster relief operations (Trunick 2005; Tatham and Pettit 2010). It is indicated that logistics "is the most expensive part of any relief operation and the part that can mean the difference between a successful and failed operation" (Van Wassenhove, p. 476, 2006). Following a severe disaster event, life-saving operations require an efficient and immediate flow of relief goods into the affected area, as well as an exchange of information (Kovács and Spens 2007). However, these areas generally face disturbed logistics as well as damaged infrastructure and communication networks, reducing access to the disaster area (Balcik et al. 2008). New approaches are crucial to deal with the increasing need for humanitarian aid.

An emerging trend in humanitarian logistics is the use of Unmanned Aerial Vehicles (UAVs). UAVs can provide solutions to the current problems associated with the distribution of relief goods. They can operate regardless the state of the infrastructure and offer the potentials to save costs and time compared to ground transportation (Rabta et al. 2018). At the moment, advanced UAV applications have mainly been considered in the commercial supply chain context and densely populated urban areas (Rabta et al. 2018). UAVs already show promising results for lightweight deliveries of medical supplies (Gilman 2014; Thiels et al. 2015). The potentials of UAVs for larger amounts of relief goods (e.g., water, food, or blankets) and the supply of goods to remote locations yet needs to be explored (Nedjati et al. 2016; Rabta et al. 2018). Furthermore, UAV applications for disaster management are studied in recent years, but mainly focus on the technological aspects rather than the optimization of UAV operations (Oruc and Kara 2018; Otto et al. 2018). Up to date, few papers have been published about delivering relief goods with UAVs (e.g., Nedjati et al. 2016; Fikar et al. 2016; Chowdhury et al. 2017; Rabta et al. 2018; Macias et al. 2020).

Some of the unique characteristics for humanitarian relief operations are mentioned by Balcik and Beamon (2008), which include (1) the unpredictability of demand, in terms of timing, location, type, and 
size, (2) very large demand and short lead times for supplies, (3) high stakes related to the timely and effective delivery, and (4) limited amount of resources. To develop and evaluate new approaches for humanitarian logistics, these unique characteristics should be taken into account. Especially the dynamic and uncertain environment is an important factor. For reviews about the uncertainty in humanitarian logistics, we refer to Liberatore et al. (2013) and Hoyos et al. (2015). They both show that the majority of the research applies stochastic programming to deal with uncertainties, in particular two-stage linear programs. However, Liberatore et al. (2013) state that these models are usually not implemented in the systems of practitioners. In practice, risk maps and imagery captured from an affected area form the base of decision-making. To bridge the gap between theory and practice, simulation is a suitable technique. Simulation studies that include the optimization and coordination of disaster response logistics and the use of geographical information of an affected area result in a higher degree of realism of a disaster situation compared to mathematical models. In addition, simulation is an excellent tool to model the dynamic and uncertain circumstances (e.g., Liberatore et al. 2013; Lechtenberg et al. 2017) and to determine the impact of disasters, response operations, and the consequences of alternative strategies (Green and Kolesar 2004). It can be the foundation on which new methods and technologies for disaster response can be developed and evaluated, since experimentation during actual disasters would be too dangerous (Green and Kolesar 2004; Lee et al. 2009). Nevertheless, in the recent review about simulation modeling for disaster management, Mishra et al. (2019) noted that applications of simulation modeling are still at an early stage.

An example of the application of simulation modeling is the work of Wu et al. (2007) and Wu et al. (2008), who developed a decision support system for emergencies, response policies, and evacuation in a city. They integrated agent based modeling, discrete event simulation, and a geographical information system (GIS). Furthermore, Lee et al. (2009) and Barahona et al. (2013) both developed a simulation and optimization framework for a humanitarian supply chain network. Lee et al. (2009) evaluated different scenarios, whereas Barahjona et al. (2013) applied robust optimization to optimize stocking policies and the truck deliveries between facilities. D'Uffizi et al. (2015) developed a simulation system with different types of vehicles and rescue workers to evaluate different policies in an emergency situation. Lastly, Fikar et al. (2016) propose an agent-based simulation model with optimization procedures for the coordination in disaster relief distribution. They considered off-road vehicles, UAVs, and road closures in the area.

Motivated by the developments in research and practice, we present in this paper a flexible and scalable simulation framework to evaluate humanitarian logistics during disaster relief operations, with a special attention to the use of UAVs. Within the framework, the logistics operations in response to various disasters and scenarios can be simulated. Geographical information and the dynamics and uncertainties of disasters can be included in the framework to build a realistic model. Hence, the framework enables what-if analysis and serves as a testbed for new methods and emerging technologies. The simulation framework is flexible and scalable in the sense that it can be applied for the evaluation of various disaster scenarios as well as for the validation of new coordination methods and transportation means, such as UAVs. The contribution of this paper is threefold: (i) the proposal of a framework to simulate the response to various disasters and scenarios, (ii) to bridge the current gap between theory and practice by modeling the dynamics and uncertainties and using geographical information, and (iii) to provide a testbed to evaluate the application of emerging technologies (e.g., UAVs) and improve future humanitarian logistics operations.

The remainder of this paper is structured as follows: In Section 2, we describe the disaster relief distribution problem and its challenges. In Section 3, we present our conceptual framework. We apply this framework in Section 4 using a case study of the distribution of relief goods after the earthquake on Sulawesi, Indonesia in 2018. We close with conclusions in Section 5.

\section{PROBLEM DESCRIPTION}

Kovacs and Spens (2007) describe three phases of disaster relief operations: preparation, immediate response, and reconstruction, whereas Van Wassenhove (2006) distinguishes four phases: mitigation, preparedness, response, and rehabilitation. Following these phases, we will focus on the response phase, which is the short period of days or weeks right after a disaster occurs. Within the response phase, we focus on the 
transportation of relief goods from regional or national humanitarian logistics hubs to the local points of distribution in the affected areas. We denote this problem of deciding which relief goods need to be transported at what time by which vehicle as the disaster relief distribution problem. The goal of this problem is to effectively deliver the required relief goods from logistics hubs to the points of distribution near affected people in a disaster area. The effectiveness of the operation can be measured in multiple possible conflicting - objectives (Comes and Van de Walle 2016). Key performance indicators that can be used as objectives in the framework are the operational costs, fair distribution of goods over the affected area, the average response time, the number of vehicles used, and the flexibility or robustness of the relief operations. Besides transport, vehicles might also be deployed to explore the affected areas.

In their review on uncertainty in humanitarian logistics, Liberatore et al. (2013) distinguish five major parameters of uncertainty: (1) demand (e.g., timing, quantity and type of goods), (2) demand location, (3) affected areas, (4) supply (e.g., prices, quality, and availability), and (5) the transportation network (e.g., capacity, availability and reliability). We want to model the dynamic and uncertain situation after a disaster realistically and, therefore, include these parameters of uncertainty. Since we focus on the last-mile distribution in the response phase, we assume that in the preparation phase, a sufficient amount of supplies is prepositioned at humanitarian logistics hubs, and we exclude the supply uncertainty.

In the early stages of the response phase, there exists large uncertainty about the impact of the disaster. Requests for relief goods dynamically evolve over time and responders have to make decisions with limited information (Comes and Van de Walle 2016). Considering this uncertainty, deliveries can depart based on two situations. To anticipate future demand, vehicles can already depart to highly populated areas where a large impact is expected, or vehicles respond to the request for demand at specific locations. Relief goods can be categorized into two main groups (Balcik et al. 2008): (i) reusable items whose demand occurs only once (e.g., tents and blankets) and (ii) items that are consumed over time (e.g., food and water). In the early stages, not only the demand is unknown, but also travel times for road vehicles are uncertain, since the impact of a disaster on the infrastructure is not yet assessed. When areas are unreachable due to road damage, or affected areas are overseas or remote, ships and aircraft might be able to reach these areas if ports or airports are operational. Also helicopters can be employed as a flexible, but usually expensive alternative to reach remote locations. UAVs are also not limited by damages to the infrastructure, and since there is not a human pilot on board, they offer a flexible and less expensive alternative, and might be saver considering rebel groups or viruses in the area. Moreover, when UAVs are equipped with cameras, they can assess affected areas and provide initial information about the infrastructure quickly.

To build a comprehensive simulation model for a specific case, we require data. Data about historical disasters can be gathered from situational reports, maps, and assessments, available at public databases such as Relief Web, MapAction, Logistics Cluster, and the Humanitarian Data Exchange, or through humanitarian organizations such as the World Food Programme or the Red Cross. The required information to be collected from humanitarian logistics information systems, as mentioned by Comes and Van de Walle (2016), include information about (i) the disaster, such as the humanitarian needs (demand for relief goods), priorities, resources, infrastructure, and accessibility, and (ii) the supply chain that distributes the relief goods including capacities, status of goods, and actors. To simulate the historical humanitarian operations, it is important to know who was doing what, where, and when, the so-called ' $4 \mathrm{~W}$ ' within humanitarian operations. These data also provide insight into the requirements for a generic simulation framework to allow for realistic modeling of affected areas. By modeling this realistically, we bridge the gap between theory and practice and evaluate the potential impact of new methods and technologies in a valid and reliable way.

\section{CONCEPTUAL FRAMEWORK}

The elements of the disaster relief distribution problem and data that can be collected from disasters form the basis of the comprehensive simulation framework. To model all necessary attributes of the humanitarian logistics response after a disaster, we define a simulation framework with six layers: (1) geographical information, (2) population and demand, (3) supply chain network, (4) vehicles and UAVs, (5) logistic 
coordination, and (6) the graphical user interface. The first three layers are input layers that provide information to the simulation model about the disaster environment. For each type of disaster and scenario, geographical information, data about the population and the demand for relief goods, and information about the supply chain network can be imported into the specific layers in the framework. The vehicles and UAVs layer and logistic coordination layer form the logistical layers, where different types of vehicles and their control can be modeled based on the specific disaster or experimental settings. The graphical user interface is the output layer, providing the simulation results over time and the key performance indicators. We will discuss each layer in more detail below.

- Geographical information. The geographical information layer includes, e.g., satellite or UAV imagery from a disaster, height maps, general road networks, and damage assessments and should be imported in the framework. These form the foundation of the disaster environment and define water, land, roads, inaccessible areas (e.g., flooded, insecure, or damaged) and limitations, and, for example, mountains. Furthermore, damage to the infrastructure can be identified from imagery of the affected area. When new imagery becomes available during the aftermath of the disaster, for example from UAVs, it can be updated in the simulation model.

- Population and demand. The second layer involves information about the population, such as the population density and the needs resulting from the impact of the disaster, which should also be imported in the framework. The needs can be distinguished in expected demand of relief goods, and the actual requests of relief goods arriving from rescue workers in the affected area. The main instances of this layer are the requests for relief goods, which consist of a location, time of arrival, amount, type of goods, and possibly the priority.

- Supply chain network. The supply chain network layer is an abstraction of the first two layers. It is a node-arc network that includes all information about the supply chain, where the nodes represent humanitarian logistics hubs, points of distribution (e.g., shelter camps), ports, and airports, and the arcs represent the shipping routes, fly routes, and driving routes that connect the nodes. For example, islands could be connected with each other by shipping and fly routes and an area in a desert can be connected with a fly route and an off-road driving route. The availability and capacity of these entities possibly change over time. Nodes that represent humanitarian logistics hubs are supply sources of relief goods, whereas the points of distribution are the delivery locations of relief goods. Port nodes and airport nodes can be regarded as intermediate warehouses, where ships, aircrafts, and trucks can be loaded or unloaded. Ports and airports can be operational, partial operational, or damaged. Based on the impact of the disaster, arcs (e.g., roads) can be accessible, limitedly accessible, or impassable due to damage. In a human-made disaster, insecurity in certain areas can also affect the condition of arcs. Furthermore, travel times and the allowable payload of vehicles can depend on the conditions of arcs.

- Vehicles and UAVs. This layer consists of the vehicles providing the transportation of relief goods. The objective of this study is to investigate how and to what extend UAVs can contribute to the humanitarian logistics operations. Vehicles transport relief goods from one location to another. Depending on the specific disaster or experiment, multiple vehicles can be introduced in this layer based on their characteristics: the transport modality (sea, road, or air), maximum payload, travel range, maximum speed, refueling or recharging time, operating hours, fixed costs, and variable operational costs.

- Logistics coordination. The logistic coordination layer involves all coordination processes. Within this layer, it is determined which tasks are allocated to which vehicles, when these tasks are executed, and in which order. The coordination layer allocates demand requests to vehicles and solves the resulting routing problem. In this layer, different types of coordination mechanisms can be modeled and evaluated (e.g., centralized/decentralized methods, alternative and novel algorithms).

- Graphical user interface. This layer provides control of the underlying layers, setting experimental factors, defining what-if scenarios, and showing the results and consequences of the simulation experiments. It presents key performance indicators, such as the average response time, demand 
coverage over time, costs of operations, and the utilization of vehicles. Furthermore, it displays the other layers such that the simulation can be followed visually.

The layered approach (Figure 1) presents a structure that can be tailored to a disaster and, thus, provides a high degree of reusability. The purpose of the generic framework is to be able to realistically evaluate humanitarian logistics operations for different disaster scenarios and to investigate the contribution of merging technologies, where we want to pay special attention to UAVs. We will analyze in which situations, in what ways, and to what degree UAVs can contribute to humanitarian logistics. With historical disasters, we can validate the model and demonstrate the added value of UAVs. This contribution cannot be based on a single case, but should be analyzed based on a diversity of historical disasters. Moreover, we do not only want to evaluate historical disasters, but also extract typical scenarios from the historical cases. With these typical scenarios, we cannot only demonstrate the added value, but also generate new knowledge and learn how to anticipate quickly and deploy UAVs effectively when the next disaster occurs.

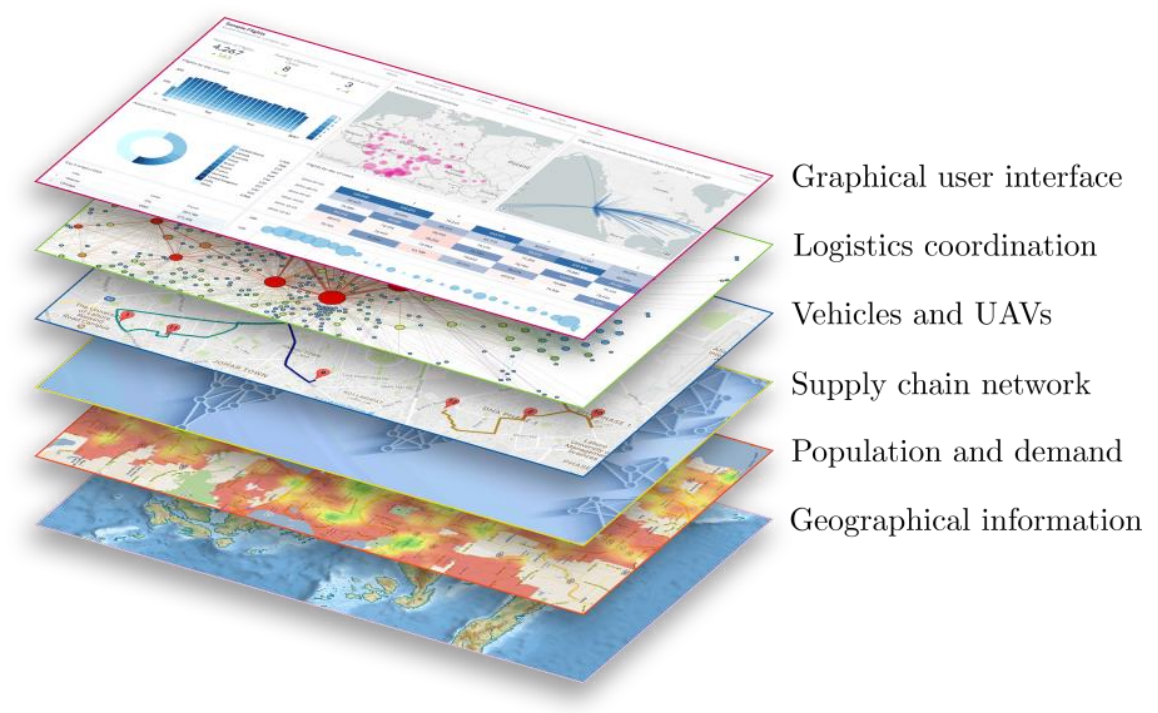

Figure 1: Layered framework for humanitarian logistics.

\section{ILLUSTRATION OF THE FRAMEWORK}

To illustrate the applicability of the framework and provide initial results of the contribution of UAVs during a disaster, we analyze a case study of the earthquake on the island of Sulawesi in Indonesia. On September $28^{\text {th }}, 2018$, a $7.4 \mathrm{M}$ earthquake occurred that caused landslides and liquefaction in the districts Donggala, Palu, and Sigi. The earthquake also triggered a tsunami damaging one of the largest cities of the island, Palu, and displacing more than 200,000 people. We consider the response during the first three weeks after the earthquake, as information was limited in the beginning and the available information about the impact, people, and accessibility increased significantly during this period. After the earthquake, relief goods were transported to the airport of Palu from the airport in Balikpapan on the island of Borneo 350 $\mathrm{km}$ away. It was reported that the incoming planes supplied 553 metric tons of relief goods between September $28^{\text {th }}$ and October $18^{\text {th }}$ to the airport in Palu (AHA Centre 2018). We assume that this was sufficient to support the affected people on Sulawesi in that period. However, congestion of relief goods at the airport was reported. The main bottlenecks of the distribution were the access constraints and logistics challenges, since damages were reported along about $50 \%$ of the main roads, and areas in the district Sigi were inaccessible for more than a week after the earthquake. Since the relief goods were already located at the local airport and areas were difficult to reach, we expect that UAVs could have made a considerable contribution to the humanitarian logistics. 
van Steenbergen and Mes

To give a complete description of the case and the way we model it, we go through the six layers of the framework in the following subsections. We describe which information is imported, which vehicles are modeled, which coordination methods we defined, and which assumptions we made for this particular case.

\subsection{Geographical Information}

We create the layer with geographical information of the affected area on Sulawesi using the GIS software ArcMap 10.7. Here we combine the satellite imagery, the road network (OpenStreetMap 2020), and information on the damaged structures (UNOSAT 2018). The tsunami triggered by the earthquake entered Palu Bay and significantly damaged Palu at the end of the bay, one of the largest cities of the island of Sulawesi. The earthquake also triggered landslides and liquefaction that damaged the infrastructure. About $50 \%$ of the roads along the coast and in the city of Palu seem to be damaged.

\subsection{Population and Demand}

To identify the locations, needs, and requests of people in the disaster area, we use the information from a joint needs assessment (Emergency Capacity Building Indonesia 2018) of the area and the data from the displacement tracking matrix (International Organization for Migration 2018). The joint needs assessment is a field assessment executed by local and international NGOs at many locations in the affected area, interviewing people in the affected area and mapping their needs. The report on the first round of the displacement tracking matrix was finished on October $19^{\text {th }}, 2018$ and was a collaboration of the United Nations International Organization for Migration and the Indonesian Government. The displacement tracking matrix mapped the shelter camps in the affected area, including the sources and needs for food, water, sanitary, and non-food items. We assume that when a joint needs assessment took place in a village, the demand is reported and transport can be planned to the camps in this village. We further assume that when a village is reported to be accessible or inaccessible for trucks, this holds for all camps in the village. When there was no joint needs assessment in the village, we take the date, time, and accessibility of the first joint needs assessment in the sub-district. If no assessment took place in the village or sub-district, we use the date, time, and accessibility of the nearest assessment based on the GPS coordinates. If an assessment took place before the camp was opened, we take the opening date as request date. We assume that when a camp becomes accessible, it remains accessible. When the village is reported inaccessible, but the sub-district is accessible, we assume that the camps in the village became accessible after three days. If also the subdistrict is inaccessible or the accessibility is unknown, we assume that camps became accessible after six days. We based this assumption on the observation that the southern sub-districts of the Sigi district were inaccessible after the earthquake and this area became accessible after six days.

As mentioned before, we consider the period of the first three weeks after the earthquake, i.e., September $28^{\text {th }}, 2018$ till October $18^{\text {th }}, 2018$. As locations for the demand for relief goods, we use the displacement tracking matrix that reported 942 camps on October $19^{\text {th }}$. We only take camps into consideration where NGOs played a part, assuming that a limited number of all organizations that were involved during this disaster could have employed UAVs for their distribution. We further narrow the selection of camps based on their requirement of shelter materials (i.e., tents, tarpaulins, blankets, beds, mats, or equipment) and if these camps depend on the distribution of food. Shelter kits need to be distributed once to each household in the camps, whereas food is a daily requirement. Based on the assessments, 345 camps are reported in this period that are requiring shelter materials from NGOs and 210 of these camps are depending on the distribution of food. Right after the earthquake, 209 of the 345 camps were unreachable by truck and after three weeks, 20 camps were still not accessible by truck.

Figure 2 (left) shows the cumulative number of camps from which a request is received and that became available over time. Figure 2 (right) shows a map of the locations of the 345 camps spread over the affected area on the Sulawesi island of Indonesia. The camps marked green were accessible upon first reporting, whereas the red camps were inaccessible. As shown in this figure, the camps are nicely located along the road infrastructure of the island, as the majority of the people in this area live in Palu, and most villages are 
located along the primary regional roads. Furthermore, the areas along the coastline, and especially Palu, are impacted the most by the tsunami that was triggered by the earthquake, where the majority of the camps is inaccessible. Interestingly, we see that a lot of camps land inwards south of Palu (Sigi district) are accessible upon first reporting. However, these camps were inaccessible from September $28^{\text {th }}$ till October $5^{\text {th }}$. The majority of the camps in the north of the affected area are also inaccessible. These areas are cut off due to landslides and liquefaction arising from the hundreds of aftershocks.
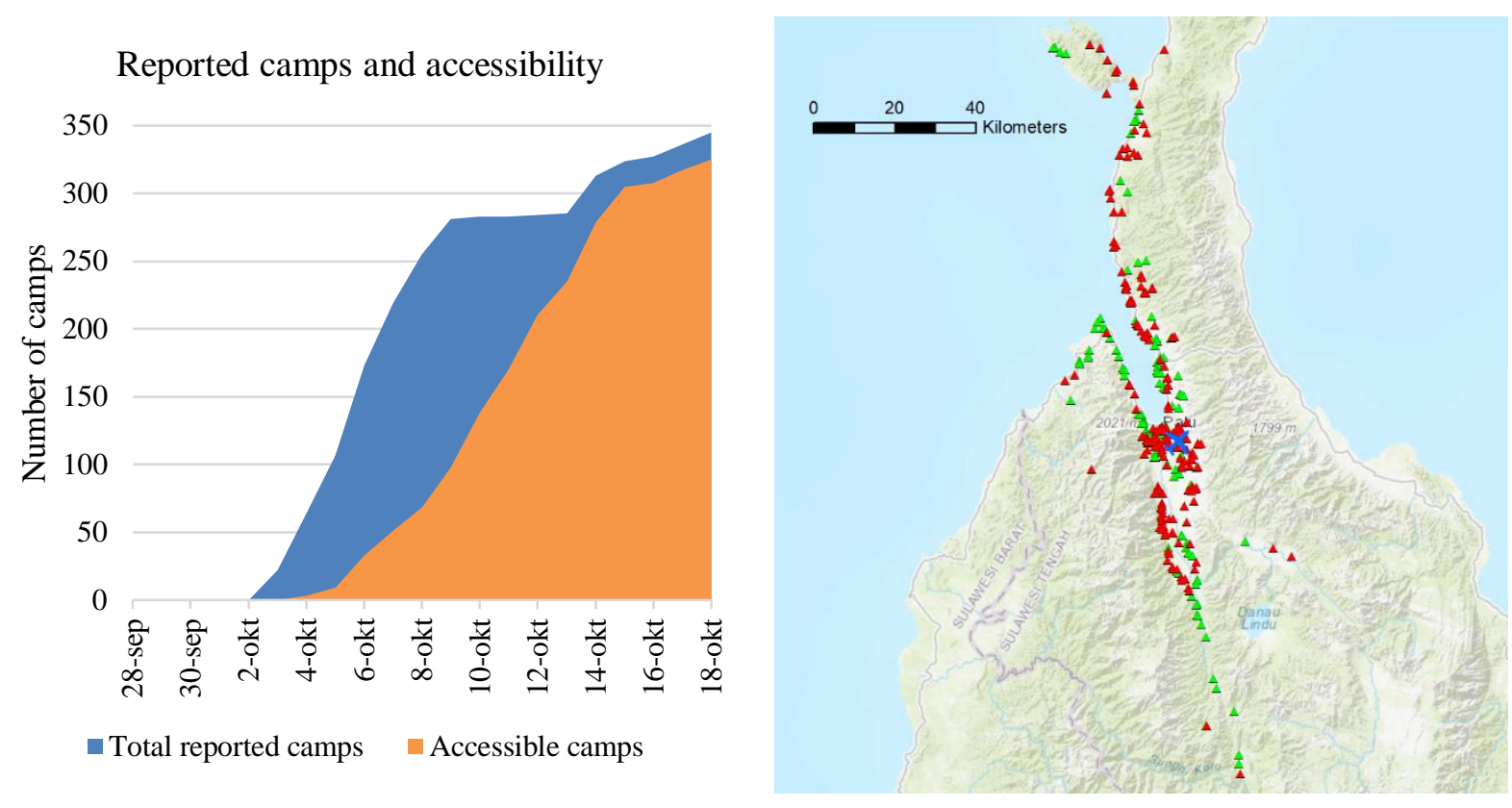

Figure 2: Reported and accessible camps (left) and camp locations in the affected area (right).

\subsection{Supply Chain Network}

In this supply chain network, the only humanitarian logistics hub is the Mutiara SIS Al-Jufrie Airport in Palu. On the airport, they used hangars and mobile storage units to store incoming relief goods. As mentioned before, we assume there were sufficient relief goods at the airport to meet the demand of the camps. However, there were difficulties reported in delivering goods due to damaged roads and bridges. Figure 3 illustrates the road network. The camps are roughly located within the city of Palu and along three roads. The roads originating from Palu lead to the sub-districts Banawa Selatan (Donggala district), Balaesang Tanjung (Donggala district), and Kulawi Selatan (Sigi district). Based on situational reports, the conditions on these roads can be generalized towards the whole section between two nodes.

Considering the damaged structures classified by UNOSAT (UNOSAT 2018), the road conditions from Palu to Banawa Selatan (A-B) are poor, with $50 \%$ of the route being damaged. Based on the fact that the travel time to Mamuju in the same direction is reported to take twice as long as normal, but still passable, we assume that the travel time is twice as long along this complete route. Along the route from Palu to Balaesang Tanjung (A-C), there are damages to bridges and landslides. Along $50 \%$ of this route damages are reported, too, but the road is still accessible for trucks with a payload up to five metric tons. Due to landslides and liquefaction, the road to Kulawi Selatan (A-D) is inaccessible after the disaster occurred. From October $5^{\text {th }}$, the road to Kulawi Selatan is reported as passable, but still damaged and limited by risks for landslides along the route due to irregularly arising aftershocks. The city of Palu is also severely damaged by the tsunami, landslides, and liquefaction. Since the roads along all network nodes have a comparable degree of damage, we assume travel times twice as long as the regular travel times for the complete road network. 
van Steenbergen and Mes

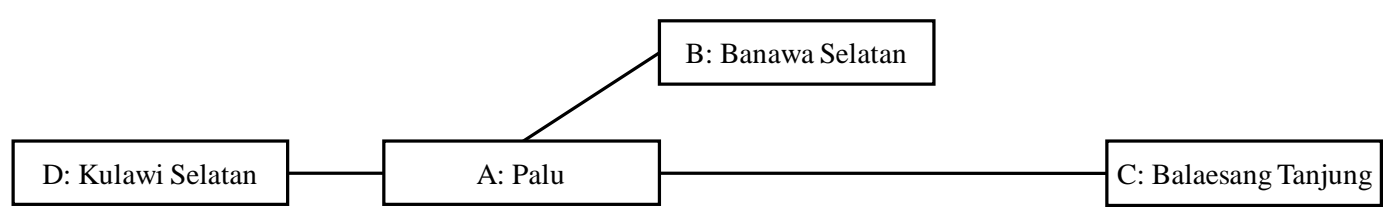

Figure 3: Simplified interpretation of the road network.

\subsection{Vehicles}

We deploy trucks and UAVs for the distribution of relief goods (Table 1). For simplicity, we assume an unlimited amount of vehicles, and vehicles are fully planned for the day. Trucks will follow the road network to reach the camps and are limited by the damages in the network. Furthermore, when a camp is categorized as inaccessible, trucks cannot deliver relief goods to these camps. The specifications of the UAVs are inspired by the remotely piloted aircraft currently in development by Wings For Aid (Aviation Pros 2020). The UAVs are not limited by damages of the infrastructure or the inaccessibility of camps, and deliver the relief goods by means of airdrop, thereby not requiring any unloading time. For the operating costs of UAVs, we consider two scenarios: $€ 150$ and $€ 250$ per hour. To fulfill the demand for relief goods, we assume that vehicles deliver shelter kits, containing $20 \mathrm{~kg}$ shelter materials for one household, and food kits, containing $20 \mathrm{~kg}$ food for 35 people for one day (WHO et al. 2002).

Table 1: Used settings for trucks and UAVs.

\begin{tabular}{lll}
\hline Attribute & Truck & UAV \\
\hline Modality & Road & Air \\
Maximum payload (kits) & 150 & 8 \\
Range $(\mathrm{km})$ & Unlimited & 500 \\
Maximum speed $(\mathrm{km} / \mathrm{h})$ & 50 & 140 \\
Costs $(€ / \mathrm{h})$ & 70 & $150 / 250$ \\
Loading time $(\mathrm{h})$ & $1: 00: 00$ & $0: 15: 00$ \\
Unloading time fixed $(\mathrm{h})$ & $0: 15: 00$ & $0: 00: 00$ \\
Unloading time per kit $(\mathrm{h})$ & $0: 00: 20$ & $0: 00: 00$ \\
Operating hours & $6: 00-18: 00$ & $6: 00-18: 00$ \\
\hline
\end{tabular}

\subsection{Logistics Coordination}

For the logistics coordination of the vehicles, we defined heuristics based on three scenarios. The heuristics are planning routes for the vehicles each day in such a way that all available camps requiring relief goods are visited. Each day, new routes are generated based on the demand of shelter camps that have become available in the past 24 hours and on camps requiring their daily food delivery. We discuss each of the three heuristics.

For the coordination of the trucks-only scenario, we apply a sequential nearest neighbor heuristic. As seed point (the first camp in the route), we take with a probability 0.5 the camp with the longest trip from the logistics hub, and otherwise the camp with the largest demand. We take the camp with the longest trip, because in that case other camps on the way can be included in the route without significantly increasing the driving time. Alternatively, we take the largest camps, because these cannot easily be added to an existing route considering the limited capacity. When capacity and time is left, the camp nearest to the last added camp will be added to the route. Camps are added to the route till the capacity limit or working day limit is reached. When the capacity limit is reached, a next trip will be planned within the remaining time. When the working day limit is reached, the next truck will be planned using a similar procedure. Trucks are planned until all requests of the accessible camps are scheduled.

For the coordination of the UAVs-only scenario, we apply a similar sequential nearest neighbor heuristics for the UAVs as for the trucks, with the exception that we use only largest distance as criteria for 
seed point and that routes are now also limited by travel range. Moreover, UAVs can reach all camps. The resulting trips typically contain only one camp per trip, and we might even have split deliveries (i.e., visiting a camp multiple times to fulfill the demand of one camp), as UAVs have a smaller capacity than trucks.

For the coordination of the combined use of trucks and UAVs, we apply a different heuristic in which we compare the costs for the delivery between trucks and UAVs. We sort the camps based on the travel costs of a truck per delivered $\mathrm{kg}$ of relief goods. The camp that is the cheapest to deliver by truck compared to the costs of UAV delivery is selected as first camp. Especially for larger camps, UAVs are more expensive per delivered $\mathrm{kg}$ of relief goods. When the first camp is selected, more camps are added to the trip if possible within time and capacity. For the next camp, we determine the marginal costs divided by the marginal $\mathrm{kg}$ of each camp. The camp with the lowest costs per $\mathrm{kg}$ to insert into the route is the next camp. These costs of the next camp are compared to the costs per kg of visiting the camp with a UAV. If a UAV delivery is not cheaper, the camp is added to the route. When no camp is available to add that is cheaper compared to a UAV delivery, the route is full. The next trip is planned in the same way, if time is still available for that truck. Otherwise, a new truck is planned with the same steps. When the first camp to be selected for a truck route is not cheaper than a UAV delivery, all remaining camps and all inaccessible camps will be scheduled for UAV delivery with the heuristic for UAVs only. In our experiments, we consider a sufficient number of UAVs. In case of a limited number of UAVs, we could give inaccessible camps priority over the other remaining camps, since the other camps can also be visited by trucks. When the limited number of UAVs are not able to visit all inaccessible camps, the camps with the lowest delivery costs per kg can be planned, and the other inaccessible camps can be scheduled during the next day. When the UAVs are also able to service some of the other remaining camps besides the inaccessible camps, camps with the lowest costs per $\mathrm{kg}$ compared to the costs of visiting the camps with a truck can also be included in the schedule of the UAVs. The remaining camps can be visited by trucks.

\subsection{Graphical User Interface}

As mentioned in Section 3, this layer controls the underlying layers. For example, here we determine the coordination heuristic and the costs settings. This layer also shows the key performance indicators and collects the results. Besides these aspects, the graphical user interface also visualizes all other layers and shows the (enlarged) vehicles moving in the affected area (Figure 4).

\subsection{Results}

An overview of the results is shown in Table 2. Trucks appear to have the lowest costs, but are unable to fulfill the demand in inaccessible camps. Furthermore, the average response time for shelter kits takes 3.5 days, whereas the UAVs require only six hours. Interestingly, there are four vehicles less required for the UAV scenarios compared to the truck scenario. Apparently, the faster operations of the UAVs are able to compensate the limited payload. The combined coordination scenarios have a comparable performance to the UAV-only scenarios, but at lower costs, and require less vehicles of each type. The increased costs for the UAV-only and combined scenarios are explained by the fact that large and inaccessible camps are visited by UAVs. Nevertheless, costs could be minimized in the combined scenarios by visiting these camps with trucks when these become accessible, but this will result in increased response times. The difference between the low and high costs for UAVs is only observed in the costs. For the combined scenarios, trucks transport more goods in the high-UAV-costs scenario. Figure 5 shows the progression of the number of vehicles deployed each day. For the truck scenario, the number per day gradually increases, since more camps become accessible every day. For the UAV-only and combined scenarios, we observe peaks from October $6^{\text {th }}$ to October $9^{\text {th }}$. At these days, also a lot of inaccessible camps are reported and UAVs are directly planned to visit these camps. For the combined scenario, the number of trucks gradually increases, whereas the number of UAVs seems to stabilize after October $9^{\text {th }}$. Hence, also when camps are accessible, some camps are cheaper to visit with UAVs. After October $9^{\text {th }}$, there are more trucks and less UAVs deployed in the high-UAV-cost scenario compared to the low-UAV-cost scenario. 
van Steenbergen and Mes

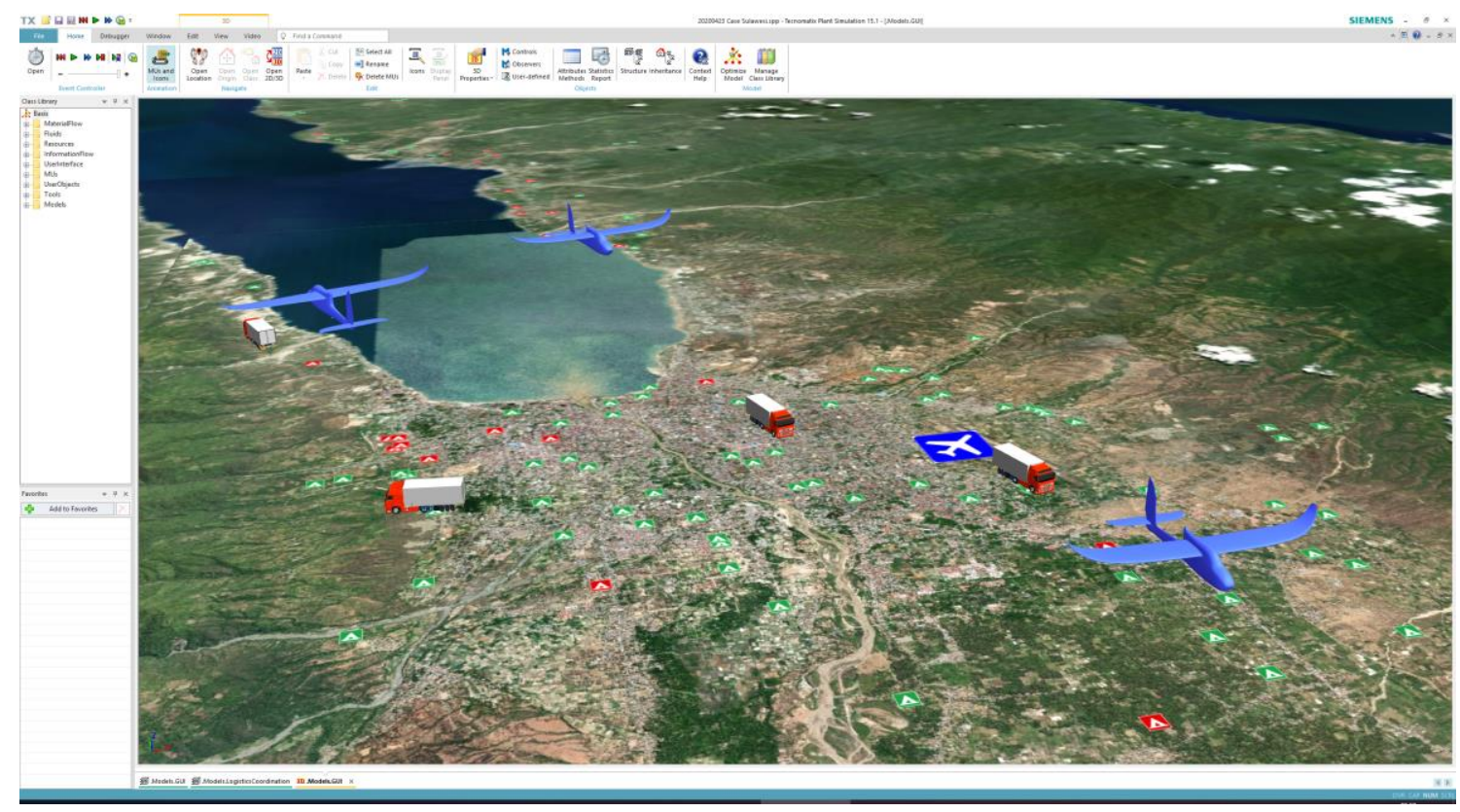

Figure 4: Visualization of the model implemented in Technomatix Plant Simulation 15.1, with the satellite imagery, accessible camps (green), inaccessible camps (red), the airport (blue), trucks, and UAVs.

Table 2: Results for the complete period.

\begin{tabular}{lrrrrrr}
\hline Scenario & Vehicle & Number & Costs $(€)$ & $\begin{array}{l}\text { Delivered } \\
\text { goods }(\mathrm{kg})\end{array}$ & $\begin{array}{l}\text { Unfulfilled } \\
\text { demand (kg) }\end{array}$ & $\begin{array}{l}\text { Shelter response } \\
\text { time (h) }\end{array}$ \\
\hline Trucks only & Trucks & 54 & 261,580 & 865,300 & 168,680 & 83,93 \\
UAVs low cost & UAVs & 50 & 413,056 & $1,033,980$ & 0 & 5,96 \\
UAVs high cost & UAVs & 50 & 688,427 & $1,033,980$ & 0 & 5,96 \\
Combined low cost & Trucks & 28 & 93,868 & 415,480 & 0 & 5,69 \\
& UAVs & 37 & 262,118 & 618,500 & 0 & 5,94 \\
Combined high cost & Trucks & 41 & 154,494 & 470,180 & 0 & 5,66 \\
& UAVs & 37 & 390,804 & 563,800 & 0 & 5,96 \\
\hline
\end{tabular}

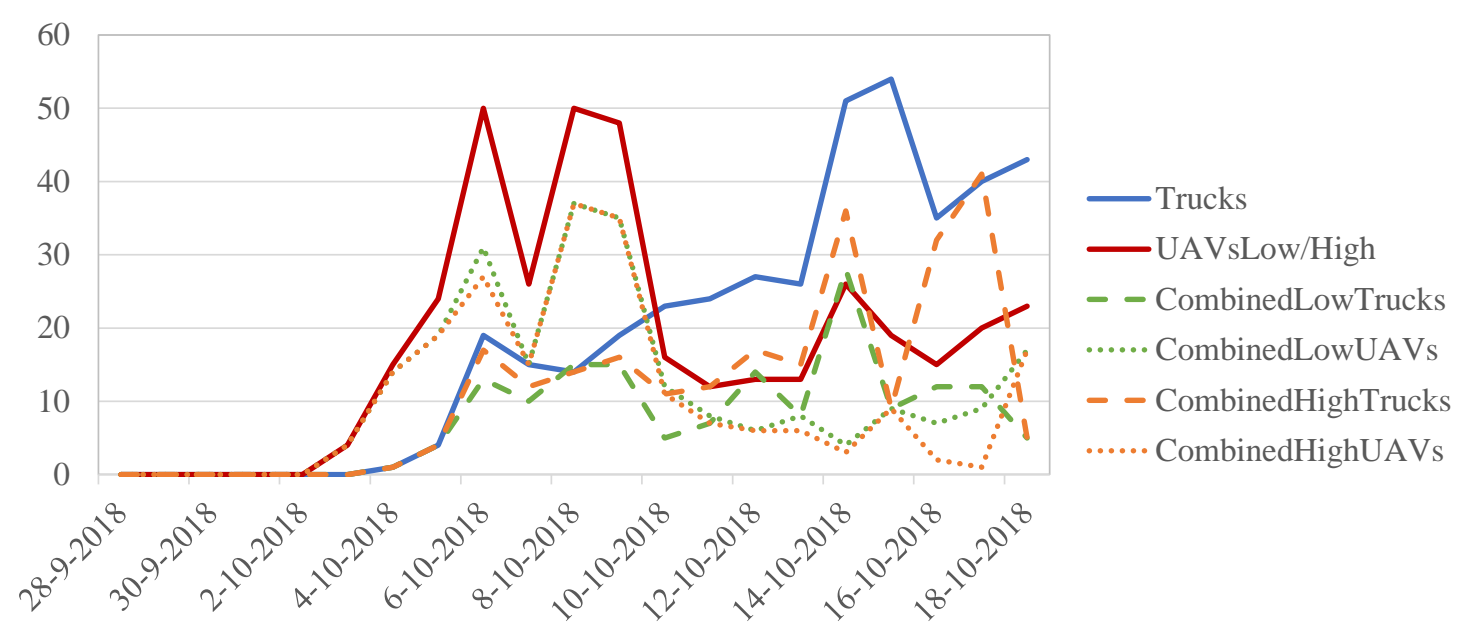

Figure 5: Number of vehicles per day. 
van Steenbergen and Mes

\section{CONCLUSIONS}

We presented a flexible and scalable simulation framework to evaluate humanitarian logistics during disaster relief operations, especially with regard to the use of UAVs. We introduced a conceptual framework with six layers that can be tailored to a specific disaster. With this approach, we can realistically analyze the humanitarian logistics response after different disaster scenarios. The purpose of the framework is to analyze, in which situations, in what ways, and to what degree UAVs can contribute to humanitarian logistics. The high degree of reusability enables the analysis of various historical disasters as well as possible future disaster scenarios. We illustrated the application of our simulation framework by modeling humanitarian logistics after the earthquake on Sulawesi in 2018, where we showed that the addition of UAVs lowers the peak of required number of vehicles. Furthermore, it can reach affected people within hours instead of days. Future research directions include the investigation of other disaster scenarios, the development of advanced coordination procedures, the analysis of more vehicles types, and including various types of uncertainty that typically occur in the period after a disaster. Furthermore, when UAVs are equipped with cameras, an interesting trade-off arises between exploiting our current knowledge to create efficient delivery schedules and exploring the affected area to collect additional information to improve future decision-making.

\section{REFERENCES}

AHA Centre. 2018. Situation Update No 13 M 7.4 Earthquake \& Tsunami. https://ahacentre.org/situation-update/situation-updateno-13-sulawesi-earthquake-19-october-2018, accessed 25 ${ }^{\text {th }}$ February 2020.

Aviation Pros. 2020. Start of Wings For Aid World Tour in Curaçao. https://www.aviationpros.com/aircraft/unmanned/pressrelease/21122748/start-of-wings-for-aid-world-tour-in-curaao, accessed $19^{\text {th }}$ March 2020

Barahona, F., M. Ettl, M. Petrik, and P. M. Rimshnick. 2013. "Agile Logistics Simulation and Optimization for Managing Disaster Responses". In Proceedings of the 2013 Winter Simulation Conference, edited by R. Pasupathy, S.-H. Kim, A. Tolk, R. Hill, and M. E. Kuhl, 3340-3351. Piscataway, New Jersey: Institute of Electrical and Electronics Engineers, Inc.

Balcik, B. and B. M. Beamon. 2008. "Facility Location in Humanitarian Relief". International Journal of Logistics 11(2): 101121.

Balcik, B., B. M. Beamon, and K. Smilowitz. 2008. "Last Mile Distribution in Humanitarian Relief". Journal of Intelligent Transportation Systems 12(2): 51-63.

Comes, T. and B. Van de Walle. 2016. "Information Systems for Humanitarian Logistics: Concepts and Design Principles". In Supply Chain Management for Humanitarians: Tools for Practice, edited by I. Haavisto, G.Kovács, and K. Spens, 257-284, London: Kogan Page.

Chowdhury, S., A. Emelogu, M. Marufuzzaman, S. G. Nurre, and L. Bian. 2017. "Drones for Disaster Response and Relief Operations: A Continuous Approximation Model". International Journal of Production Economics 188: 167-184.

Dilley, M, R. S. Chen, U. Deichmann, L. A. Lerner, and M. Arnold. 2005. "Natural Disaster Hotspots, a Global Risk Analysis, Disaster Risk Management Series No. 5". Washington: The World Bank Hazard Management Unit.

D’Uffizi, A., M. Simonetti, G. Stecca, and G. Confessore. 2015. "A Simulation Study of Logistics for Disaster Relief Operations". Procedia CIRP 33: 157-162.

Emergency Capacity Building Indonesia. 2018. Joint Need Assessment Palu Earthquake \& Tsunami, 28 September 2018. https:// data.humdata.org/dataset/raw-data-of-joint-need-assessment-palu-earthquake-tsunami-28-september-2018, accessed $25^{\text {th }}$ February 2020

Fikar, C., M. Gronalt, and P. Hirsch. 2016. "A Decision Support System for Coordinated Disaster Relief Distribution". Expert Systems with Applications 57: 104-116.

Gilman, D. 2014. Unmanned Aerial Vehicles in Humanitarian Response. Affairs. https://www.unocha.org/sites/unocha/files/ Unmanned\%20Aerial\%20Vehicles\%20in\%20Humanitarian\%20Response\%20OCHA\%20July\%202014.pdf, accessed $2^{5 \text { th }}$ February 2020.

Green, L. V., and P. J. Kolesar. 2004. "Anniversary Article: Improving Emergency Responsiveness with Management Science". Management Science 50(8): 1001-1014.

Hoyos, M. C., R. S. Morales, and R. Akhavan-Tabatabaei. 2015. "OR Models with Stochastic Components in Disaster Operations Management: A Literature Survey". Computers \& Industrial Engineering 82: 183-197.

International Organization for Migration. 2018. Indonesia Displacement Data - Sulawesi Earthquake Site Assessment [IOM DTM]. https://data.humdata.org/dataset/indonesia-displacement-data-sulawesi-earthquake-site-assessment-iom-dtm, accessed $25^{\text {th }}$ February 2020. 
van Steenbergen and Mes

Kovacs, G., and K. M. Spens. 2007. "Humanitarian Logistics in Disaster Relief Operations". International Journal of Physical Distribution and Logistics Management 37(2): 99-114.

Lechtenberg, S., A. Widera, and B. Hellingrath. 2017. "Research Directions on Decision Support in Disaster Relief Logistics". In $4^{\text {th }}$ International Conference on Information and Communication Technologies for Disaster Management (ICT-DM), December $11^{\text {th }}-13^{\text {th }}$, Münster, Germany.

Lee, Y. M., S. Ghosh, and M. Ettl. 2009. "Simulating Distribution of Emergency Relief Supplies for Disaster Response Operations". In Proceedings of the 2009 Winter Simulation Conference, edited by M. D. Rossetti, R. R. Hill, B. Johansson, A. Dunkin, and R. G. Ingalls, 2797-2808. Piscataway, New Jersey: Institute of Electrical and Electronics Engineers, Inc.

Liberatore, F., C. Pizarro, C. S. de Blas, M. T. Ortuño, and B. Vitoriano. 2013. "Uncertainty in Humanitarian Logistics for Disaster Management. A Review". In Decision Aid Models for Disaster Management and Emergencies, edited by D. Ruan and J. Montero, 45-74. Paris: Atlantis Press.

Macias, J. E., P. Angeloudis, and W. Ochieng. 2020. "Optimal Hub Selection for Rapid Medical Deliveries Using Unmanned Aerial Vehicles". Transportation Research Part C: Emerging Technologies 110: 56-80.

Mishra, D., S. Kumar, and E. Hassini. 2019. "Current Trends in Disaster Management Simulation Modelling Research 283(1): 1387-1411.

Nedjati, A., B. Vizvari, and G. Izbirak. 2016. "Post-Earthquake Response by Small UAV Helicopters". Natural Hazards 80(3): $1669-1688$.

OCHA. 2019. Global Humanitarian Overview 2020. https://www.unocha.org/sites/unocha/files/GHO-2020_v9.1.pdf, accessed $19^{\text {th }}$ March 2020.

OpenStreetMap. 2020. HOTOSM Indonesia (Sulawesi) Roads (OpenStreetMap Export). https://data.humdata.org/dataset/hotosm_ idn_sulawesi _roads, accessed $25^{\text {th }}$ February 2020.

Oruc, B. E., and B. Y. Kara. (2018). "Post-Disaster Assessment Routing Problem". Transportation research part B: methodological 116: 76-102.

Otto, A., N. Agatz, J. Campbell, B. Golden, and E. Pesch. 2018. "Optimization Approaches for Civil Applications of Unmanned Aerial Vehicles (UAVs) or Aerial Drones: A Survey". Networks 72(4): 411-458.

Rabta, B., C. Wankmüller, and G. Reiner. 2018. "A Drone Fleet Model for Last-Mile Distribution in Disaster Relief Operations". International Journal of Disaster Risk Reduction 28: 107-112.

Tatham, P. H., and S. J. Pettit. 2010. "Transforming Humanitarian Logistics: The Journey to Supply Network Management". International Journal of Physical Distribution \& Logistics Management.

Thiels, C. A., J. M. Aho, S. P. Zietlow, and D. H. Jenkins. 2015. "Use of Unmanned Aerial Vehicles for Medical Product Transport". Air Medical Journal 34(2): 104-108.

Trunick, P. A. 2005. "Special Report: Delivering Relief to Tsunami Victims". Logistics Today 46(2): 1-3.

UNOSAT. 2018. EQ20181001IDN. http://unosat-maps.web.cern.ch/unosat-maps/ID/EQ20181001IDN/EQ20181001IDN_ shp.zip, accessed $24^{\text {th }}$ February 2020.

Van Wassenhove, L. N. 2006. "Humanitarian Aid Logistics: Supply Chain Management in High Gear". Journal of the Operational Research Society, 57(5): 475-489.

WHO, UNHCR, UNICEF, and WFP. 2002. Food and Nutrition Needs in Emergencies. https://apps. who.int/iris/bitstream/handle/ 10665/68660/a83743.pdf, accessed $2^{\text {nd }}$ April 2020.

Wu, S., L. J. Shuman, B. Bidanda, M. Kelley, B. Lawson, K. Sochats, and C. D. Balaban. 2007. "System Implementation Issues of Dynamic Discrete Disaster Decision Simulation System (D4S2) - Phase I". In Proceedings of the 2007 Winter Simulation Conference, edited by S. G. Henderson, B. Biller, M.-H. Hsieh, J. Shortle, J. D. Tew, and R. R. Barton, $1127-1134$. Piscataway, New Jersey: Institute of Electrical and Electronics Engineers, Inc.

Wu, S., L. J. Shuman, B. Bidanda, M. Kelley, K. Sochats, and C. D. Balaban. 2008. "Agent-Based Discrete Event Simulation Modeling for Disaster Responses". In Proceedings of the IIE Annual Conference, May $17^{\text {th }}-21^{\text {st }}$, Vancouver, Canada: 19081913.

\section{AUTHOR BIOGRAPHIES}

ROBERT M. VAN STEENBERGEN is a PhD candidate within the department of Industrial Engineering and Business Information Systems at the University of Twente, The Netherlands. He received a MSc in Industrial Engineering in 2019. His research interests include humanitarian logistics, supply chain management, intelligent logistics, machine learning, autonomous systems, and simulation optimization. His email address is r.m.vansteenbergen@utwente.nl.

MARTIJN R.K. MES is an Associate Professor within the department of Industrial Engineering and Business Information Systems at the University of Twente, The Netherlands. He holds a MSc in Applied Mathematics (2002) and a PhD in Industrial Engineering and Management at the University of Twente (2008). His research interests are transportation, multi-agent systems, stochastic optimization, discrete event simulation, and simulation optimization. His email address is m.r.k.mes@utwente.nl. 